\title{
Formação de professores para a diversidade religiosa: qual apropriação?
}

\author{
Teacher training for religious diversity: what appropriation?
}

\author{
Claricia Otto * \\ Irma laczinski ${ }^{* *}$ \\ Fabiano Batista Rodrigues ***
}

\begin{abstract}
Resumo
Este texto é resultado de entrevistas e pesquisa com professores recém-formados em Ciências da Religião e com professores da disciplina de Ensino Religioso. Os aportes teóricos são de autores como Bourdieu com a noção de campo; Chartier com as categorias de apropriação e de representação; e, Foucault com a noção de discurso. Além de entrevistas, houve participação e observação de aulas de Ensino Religioso em uma escola estadual e no Curso semipresencial de formação continuada para professores. Nesses eventos foram produzidos registros e coletadas atividades escritas, produzidas pelos professores em formação, tanto em resposta aos Instrumentos de Pesquisa quanto às atividades propostas pelos coordenadores do Curso. Pode-se inferir que os professores, colaboradores da pesquisa, mobilizam discursos que indicam a apropriação das prescrições legais para o Ensino Religioso. Todavia, concomitantemente, aparece também a influência e permanência de questões vinculadas ao seu credo religioso e/ou a uma miscelânea de conteúdos. Além disso, podem se tornar um empecilho no estudo do fenômeno religioso na diversidade.
\end{abstract}

Palavras-chave: Ensino Religioso; Formação de professores; Apropriação.

\begin{abstract}
This text is the result of interviews and research with newly graduated teachers in Science of Religion and teachers of Religious Education class. The theoretical contributions are of authors like Bourdieu with the notion of field; Chartier with the categories of ownership and representation; and Foucault with the notion of speech. In addition to the interviews, has been participation and observation of Religious Education lessons in a State school, as well as in the continuing education course for teachers. At these events were produced records and collected written activities, produced by teachers in training, both in response to the Research Tools as well as to the activities proposed by the coordinators of the course. It can be deduce that the teachers, researchers, mobilize speeches that indicate ownership of legal prescriptions for Religious Education. However, at the same time, also exists the influence and permanence of issues linked to their religious creed and/or to a hodge-podge of content. In addition, they can become a limitation in the study of the religious phenomenon in diversity.
\end{abstract}

Keywords: Religious Education; Training of teachers; Appropriation.

Comunicação submetida em 06 de janeiro de 2018 e aprovada em 07 de agosto de 2018.

* Doutora em História. Professora do Departamento de Metodologia de Ensino e do Programa de Pós-Graduação em Educação da Universidade Federal de Santa Catarina. País de origem: Brasil. E-mail: clariciaotto@gmail.com

*** Mestre em Educação. Servidora técnica em educação do Centro de Filosofia e Ciências Humanas da Universidade Federal de Santa Catarina. País de origem: Brasil. E-mail: irma.iaczinski@ufsc.br

*** Mestrando em Educação no Programa de Pós-Graduação em Educação da Universidade Federal de Santa Catarina. Graduado em Filosofia. País de origem: Brasil. E-mail: fabianorodriguesctba@gmail.com

Horizonte, Belo Horizonte, v. 16, n. 50, p. 885-899, maio/ago. 2018 - ISSN 2175-5841 


\section{Introdução}

A escola nunca esteve completamente alheia da história da formação das sociedades e do Estado brasileiro e, por esse motivo, não pode estar alheia do fenômeno religioso, uma vez que este é integrante das sociedades e apresenta uma pluralidade de manifestações. Compreendemos que os campos educacional e religioso relacionam-se entre si na construção de um conjunto social. Na acepção de Bourdieu (2002), o campo é definido conforme suas próprias regras e princípios, em meio a conflitos e tensões, redes de relações e/ou de oposições entre agentes. É em torno de determinados valores que um grupo constrói a vida cotidiana que se rege por meio de interesses que reproduzem, legitimam, interpretam e acumulam poder simbólico, "um poder de construção da realidade que tende a estabelecer uma ordem gnosiológica” (BOURDIEU, 2002, p. 7-9).

Nesse alinhamento, aventamos que o Ensino Religioso viabiliza-se por meio de práticas de lutas e resistências, pois diferentes grupos lançam mão de uma luta pela legitimidade dos elementos simbólicos intrínsecos ao referido campo. Nossa reflexão está situada na interface entre os campos religioso e educacional com foco na formação e prática de professores de Ensino Religioso, haja vista que autores como Junqueira e Rodrigues (2014, p. 588), em pesquisa sobre a formação de professores para o Ensino Religioso no período entre 1995 e 2010, apontam “a ausência de uma reflexão sistematizada para verificação da atuação do egresso com a prática pedagógica”. Muito embora haja uma vasta produção sobre o tema em diferentes períodos, os autores sinalizam a importância da observação do contexto da sala de aula e da discussão sobre a identidade do professor de Ensino Religioso, da necessidade dessa disciplina na escola com vistas a produzir conhecimentos sobre fenômenos históricos imbricados às diferentes religiões. ${ }^{1}$ Ademais, há necessidade de promoção de diálogo intercultural e inter-religioso dado que é

\footnotetext{
${ }^{1}$ Destacamos a leitura de textos sobre a vasta produção em torno do tema em diferentes períodos, "Educação e História do Ensino Religioso", organizada por Junqueira (2015).
}

Horizonte, Belo Horizonte, v. 16, n. 50, p. 885-899, maio/ago. 2018 - ISSN 2175-5841 
crescente o desrespeito às diferentes identidades e pertencimentos religiosos no mundo contemporâneo.

Nessa direção, o tema gravita em torno das prescrições legais para a disciplina de Ensino Religioso e das práticas discursivas de docentes no estado de Santa Catarina, especificamente em Florianópolis. ${ }^{2} \mathrm{O}$ objetivo principal é identificar as apropriações de professores recém-formados do Curso de Ciências da Religião do Centro Universitário Municipal de São José (SC) e de 24 professores que atuam em escolas da Grande Florianópolis, vinculados à $18^{\mathrm{a}}$ Gerência Regional de Educação. ${ }^{3}$ Na direção apontada por Fonseca (1999, p. 10), da "interação entre o pesquisador e seus objetos de estudo, "nativos em carne e osso", observamos aulas de Ensino Religioso do professor Gustavo Dutra, na Escola de Educação Básica Cacilda Moura.4 O contato diário com o cotidiano escolar e com os sujeitos envolvidos possibilitou perceber até que ponto o prescrito para o Ensino Religioso tem sido posto em prática, quer dizer, permitiu verificar se o professor compreende a disciplina como uma área de conhecimento com epistemologia própria.

Em síntese, observamos um total de dez aulas de 45 minutos cada uma, uma vez por semana, em uma das turmas de $6^{\circ}$ ano, com 36 alunos, na de $7^{\mathrm{a}}$ série, com 35 alunos, e na de $8^{\mathrm{a}}$ série, com 37 alunos. Concomitantemente às observações em sala de aula, foram produzidos registros - Caderno de Campo com base em um roteiro. Além disso, participamos dos Encontros de Formação Continuada dos professores de Ensino Religioso da já referida 18 ${ }^{\mathrm{a}}$ Gerência Regional de Educação. Nesses encontros, os professores responderam a dois Instrumentos de Pesquisa. Desses, utilizamos aqui apenas as respostas dadas às seguintes questões contidas no Instrumento: (1) É recomendável que o professor de Ensino Religioso frequente alguma religião? (2) Quais são os conteúdos/temas que você trabalha em suas

\footnotetext{
${ }^{2}$ Para aprofundar sobre como a interpretação da Lei de Diretrizes e Bases da Educação, de 1996, e a reformulação de seu artigo 33, de 1997, condicionou o tipo de ação de agentes religiosos no processo de capacitação de professores e definição de currículo para o Ensino Religioso em SC, ver Dickie e Lui (2007).

${ }^{3}$ A pesquisa foi devidamente aprovada pelo Comitê de Ética em Pesquisas com Seres Humanos da Instituição de Ensino Superior na qual está vinculada e todos os colaboradores assinaram o Termo de Consentimento Livre e Esclarecido (TCLE).

${ }^{4}$ Nomes, do professor e da escola, são fictícios visando manter o anonimato em relação a ambos.
} 
aulas? (3) Além do que você já indicou o que mais o professor deve tratar nas aulas de Ensino Religioso?

Tomando por base as respostas dos professores, interessou-nos observar se na prática escolar contemporânea dos docentes participantes da pesquisa, há uma vertente predominante de Ensino Religioso; qual é a compreensão dos docentes acerca de seu papel ao trabalhar com o referido componente curricular; se o prescrito para o Ensino Religioso vem sendo desenvolvido na prática; quais são os materiais e metodologias utilizados em sala de aula; qual é a formação dos professores e quais são os fundamentos epistemológicos, os objetivos e os eixos organizadores do currículo.5 No primeiro tópico a seguir, são analisados os discursos dos professores acerca dos princípios que norteiam sua ação docente e de conteúdos abordados em sala de aula. No segundo tópico a ênfase está em torno da confissão religiosa professada pelos docentes, a qual influi na forma como se observou o currículo em ação.

\section{Professores de Ensino Religioso na "ordem do discurso"}

Desde a década de 30 do século XX, o Ensino Religioso passou a ter um lugar no currículo escolar juntamente com uma série de atribulados discursos favoráveis e/ou contrários a essa presença na formação escolar. A década de 1970 marca o início de investidas na formação específica de professores para esta área de conhecimento e a elaboração final da Lei de Diretrizes e Bases da Educação Nacional (LDBEN/96), juntamente com a alteração do seu art. 33 e a criação do Fórum Nacional Permanente de Ensino Religioso (FONAPER), em Florianópolis em 26 de setembro de 1995, foram marcos para o debate que se travou, desde então, em torno do Ensino Religioso escolar.

\footnotetext{
${ }^{5}$ Lages (2016, p.76)), ao se referir ao panorama atual do Ensino Religioso, de maneira ampla, aponta para a existências de três vertentes: os contrários ao Ensino Religioso na escola público em função de o Estado ser laico; os que defendem um Ensino Religioso confessional se amparando nas próprias brechas da legislação; e, os que o compreendem como área de conhecimento do fenômeno religioso.
}

Horizonte, Belo Horizonte, v. 16, n. 50, p. 885-899, maio/ago. 2018 - ISSN 2175-5841 
De acordo com a Lei $\mathrm{n}^{0}$ 9.475/97, há a obrigatoriedade de as escolas públicas brasileiras oferecerem o Ensino Religioso na grade curricular que é de matrícula facultativa, tendo, inclusive, um professor com formação específica para ministrar a disciplina. No interior de uma nova concepção e com a Resolução n. 04/10 da Câmara de Educação Básica do Conselho Nacional de Educação (BRASIL, 2010), o Ensino Religioso passou a ser um componente curricular, ou seja, passou a fazer parte das dez áreas de conhecimento elencadas pelo MEC. Com isso, os conteúdos a serem ministrados também devem ser provenientes dentre os propostos pelas normas legais. Os Parâmetros Curriculares estabelecidos pelo Fonaper (2009, p. 21-22), indicam que tal componente curricular "não deve ser entendido como Ensino de uma Religião ou das Religiões na Escola, mas sim uma disciplina centrada na antropologia religiosa". 6

Como área de conhecimento, o Ensino Religioso não se destina a ser "um espaço de doutrinação de uma ou mais denominações religiosas, o que é tarefa restrita da família e da comunidade religiosa" (FONAPER, 2009, p. 7). Dessa forma, as proposições legais sinalizam para uma necessária releitura do fenômeno religioso na diversidade, cabendo à escola ser um dos espaços nos quais se poderá propiciar formação sobre o fenômeno religioso em sua epistemologia. Brandenburg (2013, p. 222), sinaliza que a teoria do conhecimento sobre essa área ainda encontra-se em construção e que tal experiência difusa "pode despertar o questionamento sobre a necessidade de ter um objeto próprio e delimitado ou pode tornar o ER, por isso mesmo, um campo epistemológico interdisciplinar interessante". Passos (2011, p. 115), também indica que "a construção da epistemologia do ER é um grande desafio, é uma espécie de contracultura da cultura científica hegemônica que domina não somente os espaços acadêmicos, mas também as instâncias políticas reguladoras das práticas acadêmicas nos sistemas de educação”. De acordo com Passos (2011, p. 115), dentre os estudiosos

\footnotetext{
${ }^{6}$ Sugerimos a leitura de Pauly (2004, p. 179) que trata sobre a polêmica epistemológica do Ensino Religioso, indicando que "o Fonaper não enfrenta essa polêmica porque propõe um ensino religioso concebido como 'uma disciplina centrada na antropologia religiosa' [...] e tem como objeto o Transcendente". Segundo Pauly, "não parece razoável admitir a transcendência como objeto cognoscível", entre outros.
}

Horizonte, Belo Horizonte, v. 16, n. 50, p. 885-899, maio/ago. 2018 - ISSN 2175-5841 
do assunto ainda perduram "concepções científicas racionalistas, positivistas e tecnicistas" e que a "sustentação exclusivamente política do ER o coloca em [...] um lugar vulnerável, até mesmo do ponto de vista legal, que acaba vigorando ao sabor das conjunturas políticas”.

Tanto esses discursos legais sobre o Ensino Religioso quanto os discursos de especialistas e professores são práticas sociais imbricadas às relações de poder em diferentes tempos e espaços.

O discurso não é uma estreita superfície de contato, ou de confronto, entre uma realidade e uma língua, o intrincamento entre um léxico e uma experiência; [...] mas (são) práticas que formam sistematicamente os objetos de que falam. Certamente os discursos são feitos de signos; mas o que fazem é mais que utilizar esses signos para designar coisas. É esse mais que os torna irredutíveis à língua e ao ato da fala. É esse mais que é preciso fazer aparecer e que é preciso descrever. (FOUCAULT, 1986, p. $56)$.

Assim, os discursos dos professores indicam suas práticas de apropriação, as que, de acordo com Chartier (1990, p. 22), colocam “em relevo a pluralidade dos modos de emprego e a diversidade de leituras”. São ações de produção de sentidos resultantes das interações e relações estabelecidas entre o material existente, tais como textos, diretrizes, entre outros, imbricados no contexto social. Nessa direção, observamos que as apropriações e os sentidos são produzidos com base em uma leitura dos textos legais impressos, haja vista que “a ‘aplicação’ do texto ao leitor” se dá numa "relação móvel, diferenciada, dependente das variações" (CHARTIER, 1990, p. 26), seja do processo de produção do próprio texto legislativo e/ou curricular, seja das formas de leitura e apreensão e das relações com o mundo social.

Nesse sentido, os professores podem interpretar e tecer representações sobre uma mesma questão, de forma diferenciada. Relativamente aos conteúdos e princípios que devem fundamentar as aulas de Ensino Religioso, os professores indicaram que seguem os Parâmetros curriculares nacionais para o Ensino Religioso (PCNER) elaborados pelo Fonaper e pela Proposta Curricular de Santa 
Catarina. Ademais, que para realizar a docência de acordo com as prescrições legais, sabem que o professor deve ter conhecimento, neutralidade e respeito perante todas as religiões. $\mathrm{O}$ respeito às diferenças e o conceito de diversidade foram recorrentes nas falas de todos os professores.

De um lado, tomando-se um conjunto de respostas, podemos inferir que os discursos dos professores, seguem, de certo modo, uma ordem, são falas que visam organizar a realidade na qual estão inseridos. De outro, também é possível concluir que, ao se remeterem fortemente aos discursos presentes na legislação, acabam reforçando o papel desses dispositivos na organização social. Aqui, se levanta uma questão central, aquela introduzida por Foucault (2012) que, segundo Machado (1990, p. X), é a "questão do poder como um instrumento de análise capaz de explicar a produção dos saberes”. Nessa direção, há uma estreita relação entre o discurso dos professores e o poder que resulta das prescrições que, de certa maneira, controlam e regulam o que deve ser dito por eles. Ou seja, os professores indicam saber que há discursos que devem ser por eles interditados.

Suponho que em toda sociedade a produção do discurso é ao mesmo tempo controlada, selecionada, organizada e redistribuída por certo número de procedimentos que têm por função conjurar seus poderes e perigos, dominar seu acontecimento aleatório, esquivar sua pesada e temível materialidade. Em uma sociedade como a nossa, conhecemos, é certo, procedimentos de exclusão. O mais evidente, o mais familiar também, é a interdição. Sabe-se bem que não se tem o direito de dizer tudo em qualquer circunstância, que qualquer um, enfim, não pode falar de qualquer coisa. (FOUCAULT, 2012, p. 8-9).

Assim sendo, numa analogia ao estudo de Foucault a propósito das estruturas de pensamento da sociedade moderna, o discurso religioso seguiria uma ordem, tal como observamos nas práticas discursivas dos professores. Há, nos seus discursos, a existência de um ordenamento prévio relativamente aos conteúdos e princípios presentes na Lei de Diretrizes e Bases da Educação Nacional, no Fonaper e na Proposta Curricular de SC: implementação do Ensino Religioso. Os enunciados dos professores seguiram os princípios prescritos nesses documentos bem como interditaram outros elementos, tais como: proselitismo, intolerância, 
desrespeito, desconhecimento das prescrições legais para o Ensino Religioso, preconceito, entre outros correlatos. Ou seja, os professores falam exatamente aquilo que é referendado por uma “ordem” maior e que se encontra na ordem do discurso sobre o Ensino Religioso.

O que é afinal um sistema de ensino senão uma ritualização da palavra; senão uma qualificação e uma fixação dos papéis para os sujeitos que falam; senão a constituição de um grupo doutrinário ao menos difuso; senão uma distribuição e uma apropriação do discurso com seus poderes e seus saberes? (FOUCAULT, 2012, p. 42).

Ainda, nessa direção, a LDB, o Fonaper, a Proposta Curricular, entre outros documentos, também podem ser compreendidos na acepção de Foucault (2012, p. 42): “que é uma 'escritura' (a dos 'escritores') senão um sistema semelhante de sujeição, que toma formas um pouco diferentes, mas cujos grandes planos são análogos?”. Enfim, salientamos uma estreita relação entre o prescrito pela legislação e o dito pelos professores sobre como deve ser o Ensino Religioso na escola.

No entanto, nas entrelinhas de suas afirmações, observamos elementos indicando que as prescrições legais não se efetivam totalmente no currículo em ação, fugindo assim, da pretendida “ordem do discurso”, principalmente quando se trata de pensar no credo religioso assumido pelo professor.

Popkewitz (1994, p. 174), ao se referir ao currículo, indica ser ele um conhecimento historicamente elaborado com base no modo como as pessoas tornam o mundo inteligível. Para o autor, a organização do que ensinar objetiva, também, regular formas particulares de agir. Dessa maneira, 
o currículo é uma imposição do conhecimento do 'eu' e do mundo que propicia ordem e disciplina aos indivíduos. A imposição não é feita através da força bruta, mas através da inscrição de sistemas simbólicos de acordo com os quais a pessoa deve interpretar e organizar o mundo e agir nele. (POPKEWITZ, 1994, p. 186).

Vale lembrar que a legislação nacional para o Ensino Religioso foi sendo gestada em contextos de reformas da política educacional. Essas podem ser aproximadas da indicação de Silva (2006, p. 10): "o currículo é o espaço onde se concentram e se desdobram as lutas em torno de diferentes significados sobre o social e sobre o político". Nessa direção, o currículo, de certa forma, é um elemento discursivo da política em nível nacional, lugar no qual os grupos e/ou pessoas individualmente buscam fazer valer e ter força de lei sua visão de mundo, de educação, de religião, de sociedade, entre outros aspectos. Assim, as prescrições legais e a Proposta Curricular são compreendidas como textos de poder, elementos simbólicos do projeto de determinado grupo social. Enfim, de acordo com Silva (2006, p. 27), “o currículo produz, o currículo nos produz".

\section{Confissão religiosa professada pelos docentes}

Ao mesmo tempo em que os professores dizem que se pautam pelo currículo oficial, também afirmam ser importante o professor ter uma religião bem como dela participar, constatação que vai ao encontro da indicação de Junqueira (2002, p. 126):

A escolarização do Ensino Religioso no Brasil ainda não é uma realidade nacional; existe a carência de profissionais capacitados para empreender esta proposta, assim como subsídios para apoiar todo este processo. As linhas que ainda apostam na ação desta disciplina com espaço legítimo de doutrinamento é forte, muitos professores aderem a estas linhas que divergem da lei de diretrizes e o fazem não por acreditar ou desacreditar na escolarização do Ensino Religioso, mas porque não sabem o que fazer. Sempre atuaram como catequistas e não como professores, sobretudo, não têm onde buscar suporte para a disciplina como componente escolar.

Igualmente, Oliveira et al., (2007, p. 58), sinalizam que ainda é frequente encontrar docentes lecionando de "acordo com a proposta interconfessional cristã, 
inserindo algumas informações sobre outras tradições de matriz oriental, africana e indígena”. Os fragmentos a seguir, dão um indicativo dessas questões apontadas por esses autores e também sobre o conflito entre o que deve ser o Ensino Religioso, entre o ideal e o que ele é na prática, ou melhor, na concepção da maioria dos professores que responderam se era importante que o professor de Ensino Religioso frequentasse alguma religião:

Sim. Fé em Alá. [...] Foi uma missão dada por Alá. [...] Porque apenas na religião de Alá que um homem se torna digno aos olhos do Profeta (P14).7

É que nas aulas de Ensino Religioso alguns professores dão catequese (P16).

Eu creio que sim. Como posso dizer aos meus alunos que a religião dá sentido à nossa vida, que ter uma mão para nos amparar em todos os momentos de nossa vida é fundamental para sermos mais felizes, se não sou exemplo? (P8).

Como você irá falar do Sagrado se não pertence a nenhuma religião e não acredita em nenhuma delas? E se alguém vier a perguntar então pra que temos aula de ensino religioso se o professor nem sequer uma religião segue? (P9).

É sempre mais fácil compreender quando sabemos sentir ou nos colocar no lugar do outro. A experiência religiosa pode contribuir para isso. (P16).

Acho necessário que se tenha uma fé, digo uma religião, podendo ser institucionalizada ou não. (P2).

Acho necessário que se tenha uma fé, digo uma religião, podendo ser institucionalizada ou não. (P2).

Pelo curso que tenho, pois sou Pastor ( $\left.\mathrm{P}_{5}\right)$.

Porque atuei como pastor por 22 anos e sempre gostei de ensinar e continuo gostando (P6).

A influência da confissão religiosa do professor igualmente foi percebida nas aulas observadas. No primeiro dia de aula após o recesso escolar, o professor de Ensino Religioso entra nas salas de aula vestindo roupa branca, inclusive boné branco na cabeça. Informa aos alunos das três turmas que sua religião é a Umbanda e que passou por um ritual religioso, que subiu de hierarquia e que ficaria quarenta dias usando somente roupa branca. Foi indagado por apenas uma

\footnotetext{
${ }^{7}$ P significa Professor. Visando manter o anonimato, atribuiu-se um número a cada professor colaborador da pesquisa.
}

Horizonte, Belo Horizonte, v. 16, n. 50, p. 885-899, maio/ago. 2018 - ISSN 2175-5841 
aluna da $7^{\mathrm{a}}$ série se também era necessário usar toalha de cor branca. O professor respondeu que deveria usar tudo branco, toalha, lenço na cabeça e lençol. Tanto nessa como nas demais turmas, não houve mais nenhuma outra indagação a respeito. ${ }^{8}$ Esse conjunto de palavras, gestos, símbolos pode ser entendido à luz do rito de investidura que acaba exercendo uma eficácia simbólica:

De início, logra tal efeito ao transformar a representação que os demais agentes possuem dessa pessoa e ao modificar sobretudo os comportamentos que adotam em relação a ela (a mais visível de todas essas mudanças é o fato de lhe conceder títulos de respeito e o respeito realmente associado a tal enunciação); em seguida, porque a investidura transforma ao mesmo tempo a representação que a pessoa investida faz de si mesma, bem como os comportamentos que ela acredita estar obrigada a adotar para se ajustar a tal representação. (BOURDIEU, 1996, p. 99).

É interessante salientar o fato de que os professores que seguiram a "ordem do discurso", isto é, demonstraram saber dos conteúdos e princípios da disciplina correlacionados às prescrições legais para o Ensino Religioso, indicarem, concomitantemente, uma diversidade de conteúdos tratados em suas aulas:

A influência da religião na cultura. A liderança religiosa, A música nas religiões. A Reforma e Lutero. Aborto. Alcoolismo. Alteridade. Amizade. Amor ao próximo. Amor próprio. Anjos. Ansiedade. As Religiões no Brasil. As religiões primitivas. Auto conhecimento, Budismo. Bullying. Casamento. Catolicismo. Conhecer a si mesmo, expressão viva de Alá. Corrupção. Deus e deuses. Direitos e Deveres. Drogas. Espiritismo. Espiritualista. Ética. Família. Fé. Honestidade. Lei e leis. Liberdade Religiosa. Líderes Religiosos. Monoteísmo. Morte e vida. O conceito de liderança. Organização. Páscoa. Paz. Politeísmo. Pós-reforma e outras seitas mais conhecidas. Práticas Religiosas. Prevenção de doenças. Relacionamento. Religião e religiosidade. Religiões Africanas. Valores e moral. Violência. Vocação. (P. 1, 3, 5, 6, 8, 9, 11, 14, 15; E1 e E2; FC 19, 20, 22).

Essa listagem de conteúdos pode ser um indicativo de várias questões, dentre elas, a da existência de distintas concepções epistemológicas que ora se aproximam em vários aspectos com os eixos organizadores dos conteúdos do Fonaper e ora se afastam, podendo indicar falta de clareza conceitual; falta de

\footnotetext{
${ }^{8}$ Caderno de Campo, p. 24. Observação das aulas de Ensino Religioso na Escola de Educação Básica Cacilda Moura. Florianópolis, 06/08/2012.
}

Horizonte, Belo Horizonte, v. 16, n. 50, p. 885-899, maio/ago. 2018 - ISSN 2175-5841 
compreensão de que o Ensino Religioso está no âmbito da educação e não no da evangelização e pastoral e de suas crenças de acordo com seu credo religioso; a de que ao professor de Ensino Religioso é atribuída uma série de situações complexas como sendo respectivas ao seu ofício como docente da disciplina. Talvez esteja aí uma questão a ser enfrentada, à de pedir a esse professor dessa disciplina escolar mais do que ele pode proporcionar. Relativamente aos eixos centrais, prescritos para o Ensino Religioso nas escolas, é possível inferir também acerca da ausência de conhecimento sobre o Ensino Religioso como área de conhecimento com epistemologia própria, sobre a sua especificidade, isto é, o fenômeno religioso em si e em suas múltiplas expressões.

\section{Considerações finais}

Diante da miscelânea de conteúdos listados e apropriados pelos professores, percebe-se a dificuldade de traduzir de forma compreensível a dimensão teórica e conceitual do fenômeno religioso, o qual carece ser compreendido como uma ciência com princípios e métodos e o Ensino Religioso como um componente curricular. Ademais, embora se saiba que o professor seja um profissional com competências diversas, isso não significa que todas as mazelas do social devam ser tomadas como conteúdo da disciplina de Ensino Religioso. Como área de conhecimento, é preciso que haja diálogo com as outras áreas, a fim de o professor de Ensino Religioso não tomar para si a tarefa de responder a uma demanda social que, se for tratada na escola, deve perpassar o currículo escolar em sua totalidade.

Há necessidade de um maior investimento, tanto na formação inicial quanto na continuada, pois existe carência de professores habilitados e de uma política educacional menos confusa em relação à epistemologia dessa área de conhecimento. Há também os entraves da falta de estabilidade dos professores na disciplina, pois, predominam professores Admitidos em Caráter Temporário e sem formação em Ciências da Religião. 
Os professores, qual espécie de consumidores, para usar uma expressão de Bourdieu (1999, p. 40), acabam reconhecendo um capital simbólico nos especialistas da fé e se deixando controlar por eles. Alguns professores da nossa pesquisa são também especialistas no sentido dado por Bourdieu. 9

Conjecturamos que, talvez, essa visão se deva à necessidade de, os envolvidos com esta área de conhecimento, continuarem ampliando pesquisas sob o viés antropológico, sociológico e histórico. Essas pesquisas poderão qualificar, ainda mais, a releitura do fenômeno religioso, de modo a evitar a configuração de uma cultura escolar ainda centrada numa espécie de doutrinação e de catequese, haja vista que, no ambiente escolar, a religião, seja ela qual for, deve ser tomada como objeto de conhecimento.

\section{REFERÊNCIAS}

BOURDIEU, P. A economia das trocas simbólicas. 5. ed. São Paulo: Perspectiva, 1999.

BOURDIEU, P. A economia das trocas linguísticas: o que falar que dizer. São Paulo: Edusp, 1996.

BRANDENBURG, L. E. A epistemologia do Ensino Religioso, suas limitações e abrangências: a confluência da educação e da religião na escola. Interações, cultura e comunidade, Belo Horizonte, v. 8, n. 14, p. 221-229, jul./dez./2013.

BRASIL. Constituição da República Federativa do Brasil. Brasília: Senado Federal, Subsecretaria de Edições Técnicas, 2008.

BRASIL. Ministério da Educação. Conselho Nacional de Educação. Câmara de Educação Básica. Resolução n. 4, de 13 de julho de 2010. Define Diretrizes Curriculares Nacionais Gerais para a Educação Básica. Diário Oficial da União, Brasília, DF, 14 jul. 2010. Seção 1, p. 824 .

BRASIL. Ministério da Educação. Lei no 9394, de 20 de dezembro de 1996. Estabelece as Diretrizes e Bases da educação Nacional. Brasília: Diário Oficial da União, de 20 de dezembro de 1996, seção III. Disponível em:

<http://portal.mec.gov.br/arquivos/pdf/ldb.pdf>. Acesso em 27 ago. 2012.

\footnotetext{
${ }^{9}$ Especialistas, nesse caso, os professores formados em Teologia.
}

Horizonte, Belo Horizonte, v. 16, n. 50, p. 885-899, maio/ago. 2018 - ISSN 2175-5841 
CAETANO, M. C. O Ensino Religioso e a formação de seus professores: dificuldades e perspectivas. Belo Horizonte, 2007. 386f. Dissertação. (Mestrado em Educação). Faculdade de Educação. Pontifícia Universidade Católica de Minas Gerais, Belo Horizonte.

CAMURÇA, M. A. Entre as ciências humanas e a teologia: gênese e contexto do programa de pós-graduação em ciência da religião de Juiz de Fora em cotejo com seus congêneres no Brasil. In: GUERRIERO, S. (Org.). O estudo das religiões: desafios contemporâneos. 3 . ed. São Paulo: Paulinas, 2008, p. 139-155.

CHARTIER, R. A História Cultural entre práticas e representações. Rio de Janeiro: Difel, 1990.

DICKIE, M. A. S.; LUI, J. de A. O ensino religioso e a interpretação da lei. Horizontes Antropológicos, Porto Alegre, ano 13, n. 27, p. 237-252, jan./jun. 2007

FONAPER. Parâmetros curriculares nacionais: ensino religioso. 9. ed. M. Mirim, 2009.

FONSECA, C. Quando cada caso NÃO é um caso: pesquisa etnográfica e educação. Revista brasileira de educação, São Paulo, n. 10, p. 58-78, 1999.

FOUCAUlT, M. A ordem do discurso. 22. ed. São Paulo: Loyola, 2012.

FOUCAULT, M. A Arqueologia do saber. Rio de Janeiro: Forense, 1986.

JUNQUEIRA, S. R. A.; RODRIGUES, E. M. F. A formação do professor de Ensino Religioso: o impacto sobre a identidade de um componente curricular. Revista Pistis \& Praxis, Curitiba, v. 6, n. 2, p.587-609, maio/ago. 2014

JUNQUEIRA, S. R. A. Educação e História do Ensino Religioso. Pensar a Educação em Revista, Curitiba; Belo Horizonte, v. 1, n. 2, p. 5-26, jul-set/2015.

JUNQUEIRA, S. R. A. O processo de escolarização do Ensino Religioso no Brasil. Petrópolis: Vozes, 2002.

LAGES, J. A. C. Ensino do fenômeno religioso na escola pública: área de conhecimento necessária para uma sociedade secularizada. 2016. 315f. Tese (Doutorado em Ciências da Religião) - Universidade Metodista de São Paulo, São Bernardo do Campo: UMSP, 2016.

MACHADO, R. Introdução. In: FOUCAULT, M. Microfísica do poder. 9. ed. Rio de Janeiro: Graal, 1990, p. VII-XXIII.

OLIVEIRA, L. B. et al. Ensino Religioso: no Ensino Fundamental. São Paulo: Cortez, 2007. 
PAULY, E. L. O dilema epistemológico do ensino religioso. Revista brasileira de educação, Rio de Janeiro, Anped, n. 27, p. 172-212, set./out./Nov./dez./2004.

PASSOS, J. D. Epistemologia do Ensino Religioso: a inconveniência política de uma área de conhecimento. Ciberteologia, Revista de Teologia \& Cultura - Ano VII, n. 34, p. 108124, 2011.

POPKEWITZ, T. S. História do currículo, regulação social e poder. In: SILVA, T.T. (Org.) 0 sujeito da educação: estudos foucaultianos. 5. ed. Petrópolis: Vozes, 2002, p. 173-210.

SILVA, T. T. O currículo com fetiche: a poética e a política do texto curricular. Belo Horizonte: Autêntica, 2006. 